\title{
O Sistema de Carreira e o Principio da Profissionalização
}

\section{MANOel ALVES Mendes JÚNioR}

Sob o patrocínio da Divisão de Pessoal do D.A.S.P. foram realizadas diversas palestras sôbre classificação de cargos. Prosseguindo na divirlgação dêsse ciclo de estudos, a "Revista do Serviço Público" apresenta o trabalho do Sr. Manoel Alves Mendes Júnior, chefe da Seção de Estudos Gerais da mencionada Divisão do D.A.S.P.

\section{$\mathrm{V}$}

AMos examinar na palestra de hoje os Capítulos III e IV do projeto de lei, isto é, a promoção e o acesso tal como foram idealizados pela Comissão do Plano de Classificação de Cargos no conjunto do sistema ora entregue à discussão e votação do Congresso Nacional.

Pediremos, inicialmente, a atenção dos colegas para uma parte do relatório da Comissão, onde sob o títulc "Inexistência do Sentido de Carreira e Consequente Dificuldade à Profissionalização do Funcionalismo. Sentido Precário da Hierarquia Funcional", pode ler-se, à página 16, segunda coluna do avulso que thes foi distribuído, o seguinte trecho:

"No sistema vigente, "carreira é um agrupamento de classes. da mesma profissão ou atividade, com denominação própria". Esta definição, por si só, indica o sentido restritơ de carreira para o funcionalismo público brasileiro. O "agrupamento de classes", a que se refere a lei, nada mais é que um compartimento estanque onde se sufocam e estiolam as ambições daqueles que, através do esfôrço próprio e, não raro, à custa de sacrifícios, pensaram, ao ingressar no serviço público, encontrar uma verdadeira carreira que correspondesse à natural tendência de todo ser humano, de atingir, por seu trabalho, uma situação condizente com os seus méritos e esforçơs.

$\mathrm{Na}$ ausência de um plano de classificação de cargos, impōe-se, no sistema vigente, o princípio, aliàs, consagrado tanto no primeiro Estatuto como no atual, de serem comuns as atribuições dos ocupantes de cada carreira, sem distinção de classes. Assim, as funções mais simples, em determinada carreira, podem ser cometidas a 
ocupantes das classes finais, da mesma forma que as mais complexas poderão ser designadas tanto àqueles, quanto aos que ainda se encontram nas classes iniciais.

Não existe, assim, hierarquia funcional nas carreiras. O funcionário que ingressa no serviço público, através de prova competitiva, por mais que se esforce, embora obtendo promoções sucessivas, não estará progredindo; em outras palavras, não estará "fazendo carreira", uma vez que, ao atingir a classe final, não terá adquirido, de forma alguma, um status mais elevado do que o colega recémadmitido no serviço público. Sem uma modificação radical do sistema, estaria o serviço público civil brasileiro fadado a perder aos poucos tôda atração para os elementos mais qualificados, que passariam a ver em outros cempos de atividade, maiores e mais sedutoras perspectivas de carreira".

Pouco teríamos a acrescentar a estas palavras, não fôsse o empenho de repisar, perante os colegas, a diferença fundamental que distingue os dois sistemas: o atual e o proposto. No primeiro, em que a promoção se resume em simples acréscimo de vencimentos, e as linhas de acesso não inexistentes. a carreira é uma ficção, ou melhor, simples conceito legal em conflito com $\sigma$ significado da profissionalização, entendida esta como a abertura aós indivíduos de tôda uma gama de oportunidades de progredir, desde as tarefas mais elementares até aos altơs cargos da administração. No último, a carreira perde êsse caráter estanque e de confinamento a algumas classes, sem perspectivas nem estímulos de progresso para o servidor, transformando-se em múltiplos e * variados ensejos ao alcance dos capazes e ambiciosos.

Em síntese, se me fôsse permitido elaborar conceitơs nesta ocasião, diria eu que, no sistema novo, "carreira" é um conjunto de classes e séries de classes, com atribuições próprias e definidas para os seus diferentes cargos, que o funcionário apto a exercê-las poderá percorrer por promoção ou acesso. Como o cargo, no sistema proposto, é um conjunto de deveres, atribuições e respon-, sabilidades, que, para os fins da classificação, só apresenta diferenças de dificuldade ou responsabilidade de uma classe para outra, a promoção e o acesso, no futuro, serão os instrumentos hábeis para concretizar, no serviço públic ว federal, o postulado da profissionalização.

Sabemos que, no sistema atual, a promoção não representa qualquer elevação na hierarquia funcional, mas simples acréscimo dè vencimentos ao passar o funcionário de classe a classe, o que importa em falsear o conceito de promoção, pois a cada elevação de vencimentos não corresponde nível mais elevado de dificuldade ou responsabilidade de atribuições.

Muito embora a Lei . $^{\circ} 284$, de 28 de outubro de 1936, introduzisse a idéia de profissionalização no serviçc público, a verdade é que o conceito de carreira estabelecido em 1939 pelo nosso primeiro Estatuto liquidou com as tentativas feitas em prol da carreira sinônimo de profissão.

Não constitui, pois, novidade em matéria de administração do pessoal afirmar-se que a reforma de 1936 , muito embora tenha representado um gran- 
de progresso na sistematização dos assuntos dơ pessoal, falhou, todavia, ao nãc propiciar as indispensáveis premissas à profissionalização no serviço público.

Com a promoção e o acesso tal como foram previstos no projeto de lei, já podemos falar em carreira no serviço público federal como portadora de um sentido novo, universal, desembaraçado das limitações ora fixadas em lei. A promoção elevará o funcionário, pelo princípio de merecimento, às classes superiores da profissão que abraçou. Exigirá, como fixa com grande pro. priedade 0 artigo 13 do projeto de lei, capacidade, eficiência, assiduidade, pontualidade, espírito de colaboração, ética profissional, e compreensão de deveres, bem como a posse de qualificações e aptidões necessárias ao desempenho das atribuições da classe superior.

$E^{\prime}$ certo que o processamento da promoção no futuro depende de regulamentação, estando, portanto, imprevisível nos seus detalhes, mas podemos desde já acentuar que o funcionário, no exercício do cargo de sua classe, estará de fatơ elaborando, através de sua própria atividade funcional, não o merecimento para ser apenas aumentado, como ocorre atualrnente, mas, sim, construindo sua posição na lista anual de merecimento que the possibilitará, em caso de vaga, a elevação a um novo cargo de maior nível de vencimentos e, também, de maior dificuldade e responsabilidade de atribuições.

Como êsse merecimento. definido no artigo 13 do projeto, tem um valor absoluto, mensurado através dos padrões fixados na regulamentação, não é mais concebível que em caso de ocorrênsia de vaga seja elaborada lista com três, cinco ou mais nomes para entregar a escclha ao arbítrio da autoridade competente para promover. A lista já estará elaborada de antemão e a promoção incidirá, como simples ato de rotina, sôbre o primeiro que à encabece.

O acesso é a outra peça fundamental do sistema de profissionalização previsto no Plano e não deve ser nivelado ao seu homônimo de que é objetơ o artigo 255 da Lei n. ${ }^{\circ} 1.711$, de 28 de outubro de 1952 . Com efeito, o acesso de que trata o Estatuto dos Funcionários, na ausência de um Plano de Classificação, baseou-se num critério puramente nominal, sem qualquer fundamento de sentido concreto ou racional.

Implantado o Plano, o funcionário poderá ter acesso a cargo de classe de nível mais elevado pertencente a série de classes afim ou correlata, afinidade esta já agora objetivamente caracterizada e registrada nas especificações de classe.

Essa afinidade poderia levar o observador superficial à impressão errônea de que as séries de classes destinadas ao acesso poder-se-iam transformar em simples prolongamento das séries de classes inferiores; é importante acentuar, todavia, que elas não se confundem, pois é mantida a exigência de concurso para que sejam apreciados, em caráter competitivo, a experiência funcional, os estudos ou trabalhos especializados e outros elementos significativos da atividade profissional do funcionario, além das exigências legais e qualificações que couberem em cada caso.

Assim, depois de candidatar-se ao acesso, o funcionário submeter-se-á ao concurso que lhe fôr exigido, através do qual, atualizando seus conhecimentos, demonstrará experiência funcional e cumprirá as exigências legais esta- 
belecidas; comprovará capacidade e revelará ambição, entendida esta no bom sentido positivo da palavra.

Além da promoção pelo princípio do merecimento, que é considerada promoção vertical porque representa, a par do aumento de vencimentos, o exercício de funções mais complexas, o projeto estabelece um aumento periódicu, tècnicamente chamado "progressão horizontal", o qual na verdade substituirá a atual promoção por antiguidade, com vantagem manifesta para o funcionário, pois, enquanto a atual promoção por antiguidade depende da existência de vaga, a progressão horizontal exige apenas o decurso de tempo. Os inconvenientes do atual sistema, que levam o funcionário com freqüência a esperar seis, oito e até mais anos por uma promoção, desaparecem com a periódica concessão dos aumentos trienais.

O novo sistema, no que diz respeito a promoção e acesso, vai exigir, inegàvelmente a elaboração de regulamentos que permitam à administração cumprir as novas disposições legais. Iremos ter, portanto, um novo regulamento de prcmoção e outro para o acesso, onde, fatalmente novos conceitos surgirão e alguns já velhos vestirão novas roupagens. O projeto já consagra um novo sentido para merecimento, mais ou menos nas bases do que por fôrça do dispositivo legal aplica-se atualmente aos casos de acesso das chamadas carreiras auxiliares às principais. De futuro, entretanto, será necessário estabēlecer-se distinção clara entre as duas formas de provimento, a fim de que promoção e acesso não se venham a confundir. Um dos pontos básicos dessa diferenciação é que para a promoção teremos de apurar merecimento, ao passo que o acesso reclamará a verificação de aptidões.

O mecanismo da promoção, muito embora requeira regulamentação, na verdade já está, em linhas gerais esboçado no projeto. A leitura do capítulo respectivo demonstra um progresso notável em relação ao sistema atual. A responsabilidade individual de cada chefe na avaliação do merecimento, caso por caso, opõe o projeto a avaliação coletiva em reunião de chefes, criando um novo tipo de apuração de merecimento. Assim é que o chefe avalia o merecimento de seus funcionários e opina sôbre a avaliação dos demais chefes; o diretor julga o merecimento à vista dos elementos informativos fornecidos pelos diferentes chefes e pelo representante $d c$ funcionalismo, na forma prevista no projeto. Portanto, o julgamento individual dos chefes cederí lugar ao sistema colegiado, com responsabilidade coletiva.

Outra vantagem no mecanismo proposto reside no processamento da promoção: ao preenchimento perićdico de um boletim e à apuração do merecimento tôda vez que haja ocorrência de vaga sucederá a elaboração de uma lista anual, que transformará a promoção no simples ato de preparaçäo de expediente de promoção do funcionário que estiver na vez.

A elaboração dos Planos de Classificação e Remuneração, concebidos êstes como duas unidades distintas mas tècnicamente vinculadas, além de permitir no futuro o exame separado ou em conjunto dos problemas de um e outro assuntos, acarreta desde a sua implantação o estudo do entrosamento do sistema de promoção proposto com a tabela de remuneração, no nosso caso a constante do Anexo VI do projeto. 
Desde já, sabemos que o funcionário promovido perceberá, na classe superior, o vencimento correspondente, no novo nível, à referência que ocupava na classe inferior.

A prática quotidiana, todavia, é que irá demonstrar como reagirá o sistema de pagamento em todos os casos que se apresentarem durante a administração do Plano. Numerosas hipóteses formuladas durante a discussão do capítulo da promoção, muito embora não afetassem o sistema, demonstraram, todavia, que serão muito fortes as repercussões do novo plano de pagamento, pelo que apresenta de inédito em relação ao anteriơr.

Convém, finalmente, dizer alguma coisa sôbre os intersticios fixados no Projeto de Lei para a promoção e o acesso.

O funcionário estará obrigado no futuro, caso o Projeto nesse particular mereça aprovação, a permanecer três anos na classe, período êsse que poderá ser reduzido a dois anos, caso não haja algum concorrente com maior antiguidade. E' um período ideal, necessário à aquisição de experiência ou especialização e não deve ser confundido com o interstício atualmente exigido, que é de um ano.

A duração do interstício quer atualmente, quer no futuro, que para muitos funcionários tem uma importância a nosso ver exagerada, como problema de administração de pessoal não chega a ocupar a nossa atenção. Na realidade, a promoção do funcionário público federal depende menos da duração do interstício do que da ocorrência de vaga .

Se atualmente o interstício é de apenas tresentos e sessenta e cinco dias, é bom não esquecer que se trata de um período mínimo de permanência numa classe que se distingue das outras superiores apenas pelo vencimento, pois suas atribuições são idênticas.

Futuramente, entretanto, é bom ter sempre presente que de classe a classe as carasterísticas variarão, reclamando exigência de especialização ou experiência que, evidentemente, só o decurso do tempo poderá satisfazer.

Cremos, pois, com esta explanação sumária, ter transmitido, como era nosso objetivo, iceéias gerais sôbre profissionalização, promoção e acesso, progressão horizontal, mecanismo de promoção, interstício e outros pontos de interêsse para o trabalho futuro dos colegas presentes, relacionados com o novo sentido de carreira, tal como concebida no projeto.

\section{SUMMARY}

1) In the Brazilian current system of personnel administration career has the narrow sense of a छrouping of olasses belonging to the same profession or activity. This system stifles ambition, since it does not give Status to the employee.

2) At present promotion amounts to mere raise of salary, lines of access are nonexistent, and a career is a fiction. Under the proposed system, a career is a set of grades and series of grades, with corresponding well-defined duties position open to emplovees capable of exercising them through promotion or access. Since each is a set of duties, and responsibilities which only differ in difficulty or responsability from grade to grade, promotion and access shall allow the establishment of professionalization. 
3) Under the new system, promotion by merit shall raise the employee to the highest grades in his carreer; it shall be automatic, effected throush choice from a permanent annual list of employees graded by merit.

4) An employee shall be able through competition to gain access to a higher grade belonging to a similar or correlated series of grades.

5) While vertical promotion, i.e. by merit, shall imply the rising of salary corres. ponding to the exercise of more and more complex functions, horizontal frogression shall consist of a series of raises based upon seniority.

6) It is important to distinguish between promotion and access: the former requires the estimation of merit, while the latter, the testing of aptitudes.

7) The proposed mechanism of promotion has the advantage that it replaces individual by collective judgement of merit by supervisors and that it becomes routine.

8) Each employee shall be required to remain in a specific grade for an interval of 3 years in order to gain the necessary experience.

A história da evolução da administração científica até a presente data reclama uma palavra de advertência. O modo de funcionamento da administração não deve ser confundido com a sua filosofia fundamental. Precisamente, o mecanismo que produzirá, em um caso, resultados desastrosos, em outro, trará os maiores benefícios; assim, a serviço dos princípios fundamentais da administração científica, alcançará o melhor êxito, enquanto conduzirá a falência ou insucesso, se for erroneamente orientado. Centenas de pessoas têm confundido o mecanismo do sistema com sua essência."

F. W. TAYLOR - Principios de administração científica. 